Article

\title{
Differences in the Development of Internal Reproductive Organs, Feeding Amount and Nutrient Storage between Pre-Diapause and Pre-Reproductive Harmonia axyridis Adults
}

\author{
Qiao Gao, Bing-Xin Wei, Wen Liu ${ }^{\circ}$, Jia-Lu Wang, Xing-Miao Zhou and Xiao-Ping Wang *(i) \\ Hubei Key Laboratory of Insect Resources Utilization and Sustainable Pest Management, College of Plant \\ Science and Technology, Huazhong Agricultural University, Wuhan 430070, China \\ * Correspondence: xpwang@mail.hzau.edu.cn
}

Received: 13 June 2019; Accepted: 1 August 2019; Published: 6 August 2019

check for updates

\begin{abstract}
Diapause control is one of the successful methods for long-term cold storage of biological control organisms without decreasing their fitness. Sufficient preparation before diapause is essential for successful diapause initiation and maintenance. Harmonia axyridis, an important biocontrol agent in its native place, can enter reproductive diapause for overwintering. However, the key preparatory events before diapause in $\mathrm{H}$. axyridis, such as specific developmental trajectory, timing, and physiological changes, remain unclear. We compared differences in the development of internal reproductive organs, feeding amount and nutrient storage between pre-diapause and pre-reproductive adult $H$. axyridis which had been reared at $20^{\circ} \mathrm{C}$ under a short-day (10L:14D) and long-day (14L:10D) condition, respectively. The results showed that there were obvious morphological differences in internal reproductive organs of diapause and reproductive $H$. axyridis. The development of internal reproductive organs was suppressed at early adult stage in pre-diapause beetles compared to pre-reproductive beetles. Feeding amount in both pre-diapause and pre-reproductive beetles increased for more than ten days after eclosion. The feeding amount of pre-diapause beetles sharply decreased from the 15th day after eclosion in females and the 14th day after eclosion in males, which implied the initiation of diapause. During the pre-diapause stage, carbohydrates and lipids were mainly accumulated by females, whereas males mainly accumulated carbohydrates. Our results not only provide basic information about the diapause process of pre-diapause stage, but also give tips to better utilization of diapause strategy during mass production and storage of $H$. axyridis.
\end{abstract}

Keywords: Harmonia axyridis; diapause; photoperiod; internal reproductive organs; feeding amount; nutrient storage

\section{Introduction}

The multicolored Asian lady beetle Harmonia axyridis is a well-known biological control agent for aphids and coccids in its native places, such as Japan and China [1-4]. Although H. axyridis is considered as an invasive species in Europe and North America [5-8], it is commercially reared and widely used as a biocontrol agent in its native places, due to its strong ability to control aphids and its environmental adaptation $[4,9]$. One of the most important environmental adaptation strategies for $H$. axyridis is reproductive diapause. H. axyridis enters a long-term reproductive diapause phase to avoid adverse environmental conditions and maintain population during the overwintering process [10-13]. The mechanism used by diapause insects to survive low temperatures provides new ideas for cold storage of commercially viable biological control organisms [14]. Long-term cold storage of some parasitoids, such as Trissolcus basalis, Telenomus podisi and Habrobracon hebetor, has been successfully 
achieved by inducing diapause, without decreasing their fitness [15-18]. Recent research showed that field-collected overwintering $\mathrm{H}$. axyridis can be stored at $3^{\circ} \mathrm{C}$ for 150 days with no subsequent loss of fitness [18], which implies the possibility of long-term storage of commercial mass reared H. axyridis by inducing diapause. However, the diapause characteristics of $H$. axyridis remain largely unknown. A better understanding of the diapause strategy of $H$. axyridis could help us improve the mass rearing and storage of the species for biological control.

Previous studies have indicated that $H$. axyridis is a temperate insect with facultative winter diapause, and that both sexes can enter diapause under short-day (SD) conditions [10,19-21]. Diapause beetles are characterized by decreased respiration, an undeveloped ovary, and a well-developed fat body $[10,22]$. Before $H$. axyridis enters diapause, it undergoes diapause induction and preparation stage [23]. The early adult stage of $H$. axyridis is the most sensitive stage to photoperiod and the photoperiod experienced by the pre-imaginal stage has no significant effect on the diapause induction [22]. More than $90 \%$ of beetles entered diapause when the newly emerged adults reared at $20{ }^{\circ} \mathrm{C}$ under a SD (10L:14D) condition for 20 days, whereas those reared under a long-day (LD) (14L:10D) condition at the same temperature became reproductive [22]. Although the environmental induction of diapause in $H$. axyridis has been well documented, little is known about the specific trajectory of reproductive development, timing, and physiological changes that occur during the pre-diapause stage.

Insects often undergo arrested development during the pre-diapause preparatory stage [24-26], along with the accumulation of lipids, carbohydrates, and proteins $[27,28]$. Insufficient diapause preparation can cause insects to fail to enter diapause, advance the termination of diapause, or die during diapause $[27,29]$. In order to uncover the pre-diapause preparatory events in H. axyridis, we compared the internal reproductive organs, developmental trajectories of the ovary, vas deferens, ejaculatory duct and male accessory glands, and daily feeding amount and nutrient storage, between pre-diapause and pre-reproductive adults.

\section{Materials and Methods}

\subsection{Insects}

More than 100 female and male H. axyridis of the Red-nSpots color pattern [30], which is the dominant local population [31], were collected in Wuhan, China, May, 2018 ( $\left.30^{\circ} 28^{\prime} \mathrm{N} 114^{\circ} 21^{\prime} \mathrm{E}\right)$. Offspring of these insects were reared in the laboratory at $25^{\circ} \mathrm{C}$, under a $14 \mathrm{~L}: 10 \mathrm{D}$ photoperiod and fed on pea aphids, Acyrthosiphon pisum. Two hundred larvae were reared in a $40 \times 40 \times 40 \mathrm{~cm}$ cage containing broad bean Vicia faba seedlings infected with pea aphids. Foods were always offered ad libitum. Photoperiod treatments were initiated after pupation, as the pre-imaginal stage is insensitive to photoperiod [22]. Fresh pupae were moved to an incubator (HP-250-GS, Wuhan Ruihua Instrument and Equipment, Wuhan, China) and randomly assigned two different photoperiod treatments: an LD condition (14L:10D) to induce reproductive development and an SD condition (10L:14D) to induce diapause. Pupae in both treatments were kept at $20^{\circ} \mathrm{C}$. Females and males in both treatments were segregated immediately after eclosion. Adults of the same sex were reared in transparent round boxes (diameter $10 \mathrm{~cm}$, height $5 \mathrm{~cm} ; 20$ adults per box). Fresh pea aphids were offered ad libitum and replenished daily. Female and male beetles reared at $20^{\circ} \mathrm{C}$ under a SD condition enter diapause after feeding for 20 days, whereas those reared at $20^{\circ} \mathrm{C}$ under a LD photoperiod become reproductive [22]. The beetles used in the following experiments were treated with photoperiod and rearing as described above. 


\subsection{Experimental Procedures}

\subsubsection{Dissecting and Photographing Internal Reproductive Organs}

Female and male beetles reared at $20^{\circ} \mathrm{C}$ under a SD condition enter diapause after feeding for 20 days, whereas those reared at $20^{\circ} \mathrm{C}$ under a LD photoperiod become reproductive. The internal reproductive organs of unmated diapause and reproductive beetles were dissected in a wax dish containing phosphate buffer solution (PBS) and photographed with a digital camera (Nikon D5100, Nikon Imaging (China) Sales, Wuhan, China) mounted on a stereo microscope (SMZ-t4, Chong Qing Optec Instrument, Chongqing, China).

\subsubsection{Developmental Status of Ovary, Vas Deferens, Ejaculatory Duct and Accessory Gland}

The internal reproductive organs of 10-15 beetles reared under LD and SD condition for 0 , $2,4,6,8,10,12,14,16,18$ and 20 days were dissected and photographed as described above. The developmental status of the ovary was distinguished into five stages according to Sakurai et al. (1986) [32]. The diameter of the vas deferens, ejaculatory duct, and the basal accessory gland were measured using ScopePhoto 3.0.

\subsubsection{Changes in Daily Feeding Amount}

The daily feeding amount of 15 female and male beetles from each treatment group was evaluated for 20 days using the method described by Soares et al. (2003) [33]. Beetles from each treatment group were reared individually in Petri dishes (diameter: $5 \mathrm{~cm}$, height: $2.5 \mathrm{~cm}$ ). Fifty similar sized adult pea aphids were provided daily, and the number of surviving aphids was counted after $24 \mathrm{~h}$. Aphids were replenished after each daily count. Petri dishes containing just 50 aphids without beetles served as the control. Mortality in the control was low. Daily feeding amount was calculated according to the following model (Soares et al. 2003) [33]:

$$
V_{0}=\left(A-a_{24}\right) \times r a_{24}
$$

where $V_{0}$ refers to number of aphids eaten, $A$ refers to number of aphids available, $a_{24}$ refers to number of aphids alive after $24 \mathrm{~h}$, and $\mathrm{ra}_{24}$ refers to ratio of aphids found alive after $24 \mathrm{~h}$ in the control treatment.

\subsubsection{Determination of Nutrient Content}

Nutrient storage is a consistent and significant preparatory event of diapause insects [27]. To clarify differences in nutrient storage between pre-diapause and pre-reproductive $H$. axyridis, we measured the protein, carbohydrate, and lipid content of female and male beetles from each photoperiod treatment group at $20^{\circ} \mathrm{C}$.

Sample collection. Beetles from each treatment group were sampled at $0,2,4,6,8,10,12,14,16$, 18 and 20 days after eclosion. We set 5 biological replicates for carbohydrates and protein content measurement, and 4 beetles were used for each biological replicate. Beetles from each sampling time point of the two treatment groups were collected to measure the fresh weight, and then were frozen in liquid nitrogen and stored at $-80^{\circ} \mathrm{C}$ for further measurement. We set 10 biological replicates for lipid content measurement, and 1 beetle was used for each biological replicate. Beetles from each sampling time point of the two treatment groups was collected, and quickly frozen in liquid nitrogen and stored at $-80^{\circ} \mathrm{C}$ for lipid content measurement. 
Protein content. Protein content was measured using the bicinchoninic acid (BCA) system [34] according to the manufacturer's protocol (Jiancheng Bioengineering Institute, Nanjing, China, Code A045-3). Briefly, samples were weighted and homogenized with precooling PBS (1 g insect $/ 9 \mathrm{~mL}$ of PBS). Then, $1 \mathrm{~mL}$ of the homogenate was transferred into new tubes and centrifuged at $2500 \mathrm{rpm}$ at $4{ }^{\circ} \mathrm{C}$. The supernatant was harvested and measured according to the manufacturer's protocol. Absorbance was measured with a microplate reader (Bio-Rad, Xmark, Berkeley, CA, USA) under $450 \mathrm{~nm}$. Protein content was then calculated according to the manufacturer's protocol.

Carbohydrate content. Carbohydrate content was measured using the anthrone-sulfuric acid method following the method described by Dubois et al. (1956) [35]. Briefly, samples were weighted and homogenized with precooling PBS (1 g insect $/ 9 \mathrm{~mL}$ of PBS) and $400 \mu \mathrm{L} 10 \%$ trichloroacetic acid. Then, $1 \mathrm{~mL}$ of the homogenate was transferred into new tubes and centrifuged at $5000 \mathrm{rpm}$ at $4{ }^{\circ} \mathrm{C}$. The supernatant was harvested and diluted 10 times with PBS. $250 \mu \mathrm{L}$ diluted solutions were then mixed with $1000 \mu \mathrm{L} 0.2 \%$ anthrone-sulfuric acid in glass tubes, the tubes were placed in a $100{ }^{\circ} \mathrm{C}$ water bath for $10 \mathrm{~min}$ followed by a $20 \mathrm{~min}$ ice bath. The reaction solutions were then added to microplates and the absorbance measured with a microplate reader (Bio-Rad, Xmark, Berkeley, CA, USA) under $628 \mathrm{~nm}$. The carbohydrate content was calculated from a standard curve adjusted for the dilution ratio.

Lipid content. Lipid content was measured using the method described by Folch et al. (1957) [36]. In brief, samples were dried for $24 \mathrm{~h}$ at $100{ }^{\circ} \mathrm{C}$ and their initial dry weight measured on an electronic balance (OHAUS AR2140, Shanghai, China). Lipids were then extracted using a chloroform and methanol (2:1) solution for $24 \mathrm{~h}$ at room temperature. After further extraction with a new chloroform and methanol solution for $6 \mathrm{~h}$ at room temperature, the dry weight was re-measured. The difference between the initial dry weight and the dry weight after lipid extraction was regarded as the weight of the stored lipids. Lipid content was calculated as the percentage of the weight of stored lipids to the initial dry weight.

\subsubsection{Statistical Analysis}

Statistical analyses were conducted in SPSS 19 (IBM, Armonk, NY, USA). Levene's tests were used to confirm homogeneity of variance and nonparametric tests (Kolmogorov-Smirnov test, K-S test) to confirm normality. Independent-Samples $t$-tests were used to assess the significance of differences in the size of internal reproductive organs, feeding amount and nutrient storage, between treatment groups $\left({ }^{*} p<0.05,{ }^{* *} p<0.01\right)$.

\section{Results}

\subsection{Differences in the Development of Internal Reproductive Organs between Pre-Diapause and Pre-Reproductive Adult H. axyridis}

3.1.1. Morphological Differences in the Internal Reproductive Organs of Diapause and Reproductive Adult $H$. axyridis

The arrested development of internal reproductive organs is one of the most remarkable features of diapause insects [24,27]. The internal reproductive organs of diapause beetles were suppressed compared to those of reproductive beetles (Figure 1A,B). The ovary of reproductive beetles was well developed, the ovarioles were markedly swollen, and each ovariole had three visible egg chambers filled with yellow yolk, the basal chamber of which contained mature eggs (Figure 1A). In contrast, the ovary of diapause beetles was infertile and the ovarioles were filiform with no recognizable egg chambers or yolk in the ovarioles (Figure 1A). The size of the vas deferens, ejaculatory duct and accessory gland of diapause beetles were also visibly smaller than those of reproductive beetles (Figure 1B-E). 
A

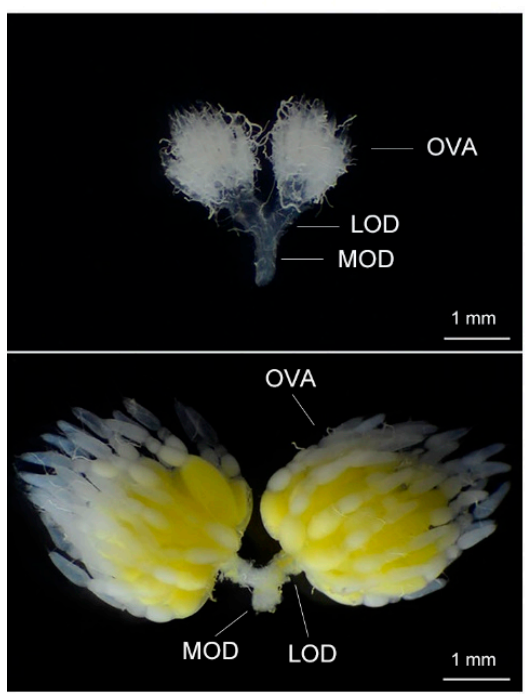

B

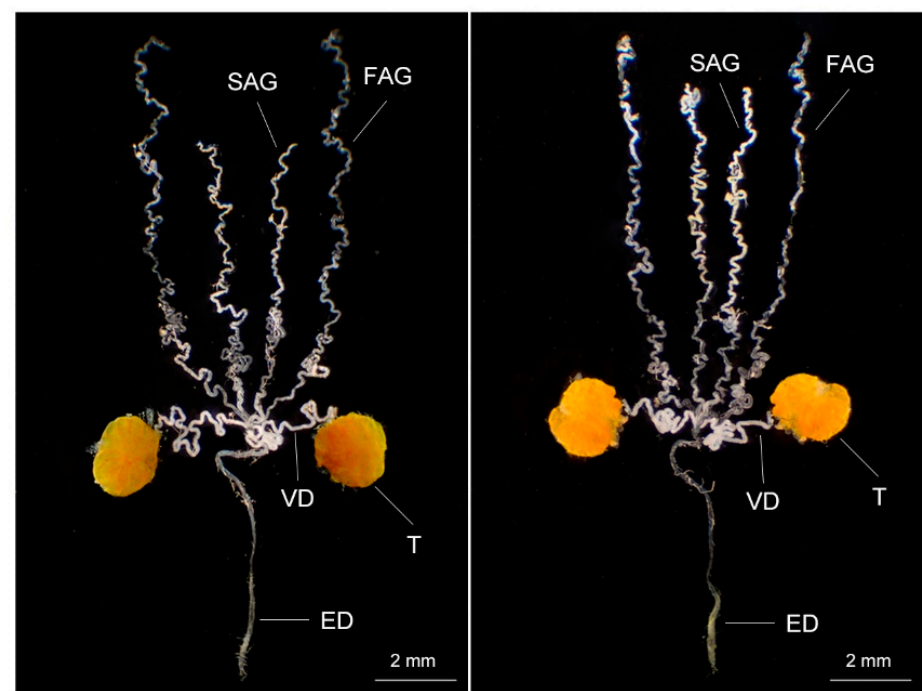

E

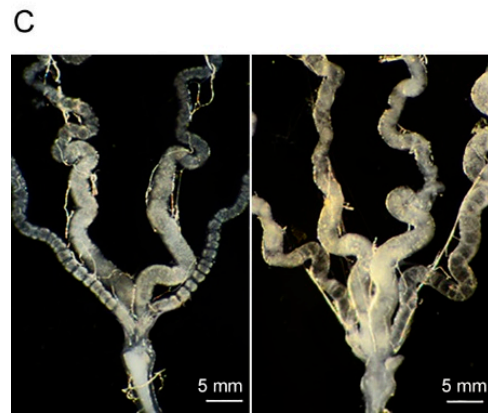

D
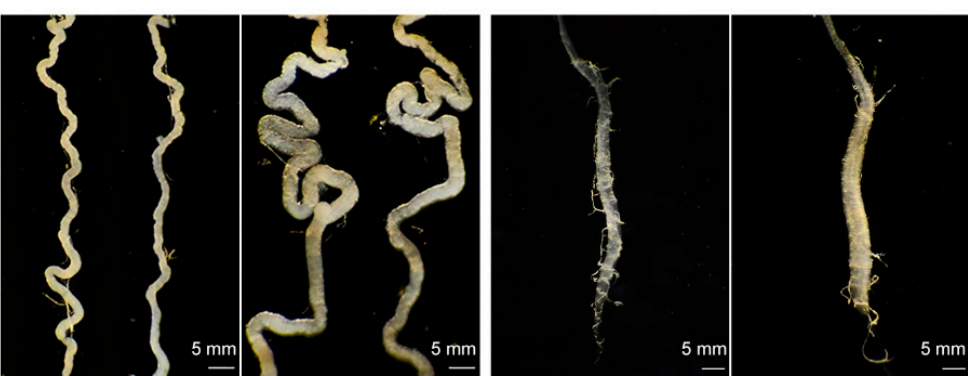

Figure 1. Morphological differences in the internal reproductive organs of diapause and reproductive adult $H$. axyridis. (A) Ovary of diapause (upper) and reproductive (lower) beetles; (B) male internal reproductive organs of diapause (left) and reproductive (right) beetles; (C) accessory gland of diapause (left) and reproductive (right) beetles; (D) vas deferens of diapause (left) and reproductive (right) beetles; (E) ejaculatory duct of diapause (left) and reproductive (right) beetles. OVA: Ovariole, LOD: Lateral oviduct, MOD: Median oviduct, FAG: First accessory gland, SAG: Second accessory gland, VD: Vas deferens, T: Testis, ED: Ejaculatory duct.

3.1.2. Differences in the Developmental Trajectory of Internal Reproductive Organs between Pre-Diapause and Pre-Reproductive Adult H. axyridis

We monitored and compared the developmental trajectory of the internal reproductive organs of pre-diapause and pre-reproductive $H$. axyridis. The ovary of pre-reproductive females developed to maturity (5th stage), while those of pre-diapause females remained immature (1st stage) (Figure 2A,B). Obvious differences in the appearance of the internal reproductive organs of pre-diapause and pre-reproductive female $H$. axyridis were apparent from 4 days after eclosion, whereas in males the differences became apparent after 6 days. The diameter of the male internal organs increased with age in both pre-diapause and pre-reproductive beetles (Figure $2 \mathrm{C}-\mathrm{F}$ ). The diameter of the first vas deferens, second vas deferens, ejaculatory duct, and accessory gland in pre-diapause males became significantly smaller than in pre-reproductive males after 12, 6 and 10 days after eclosion, respectively (first vas deferens: $\mathrm{t}=-6.225, \mathrm{df}=18, p<0.001$, second vas deferens: $\mathrm{t}=-2.215, \mathrm{df}=18, p=0.042$, ejaculatory duct: $\mathrm{t}=-2.642, \mathrm{df}=18, p=0.017$, and accessory gland: $\mathrm{t}=-2.643, \mathrm{df}=18, p=0.017$ ) (Figure 2C-F). 

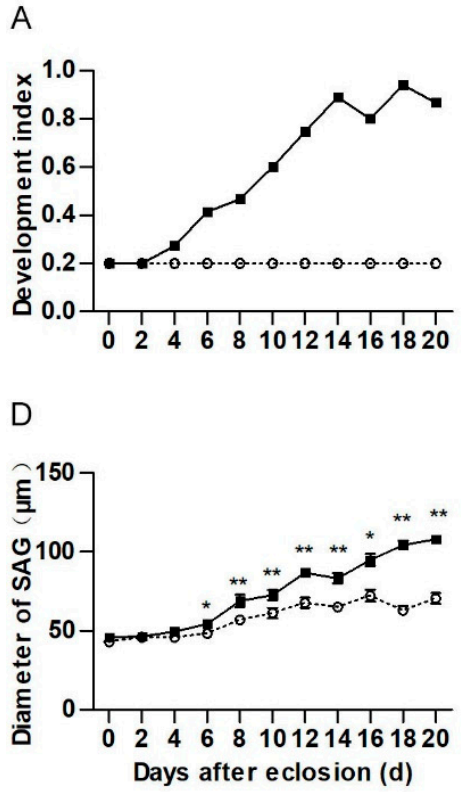

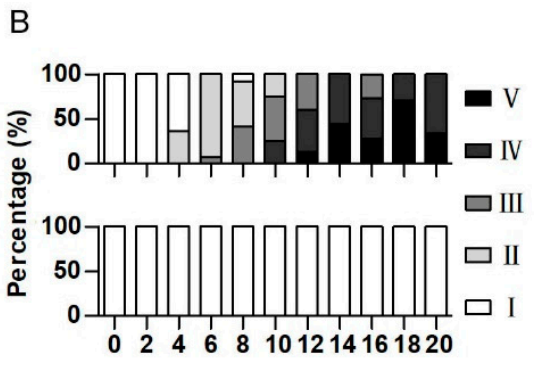

E

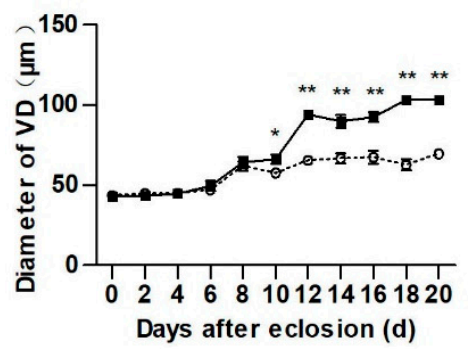

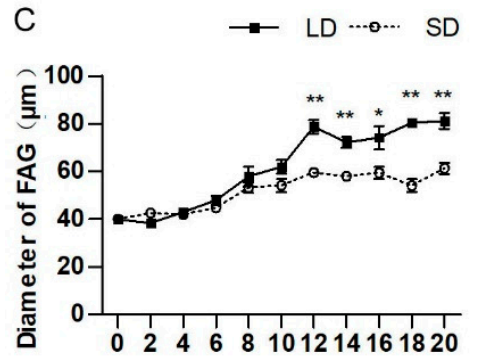

$\mathrm{F}$

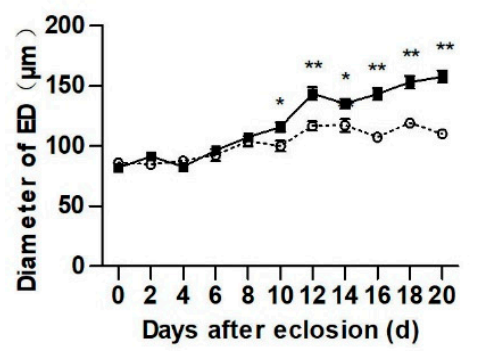

Figure 2. Differences in the development of internal reproductive organs in pre-diapause and pre-reproductive adult $H$. axyridis. (A) Developmental trajectory of the ovary in pre-reproductive (LD) beetles reared under a long-day condition and pre-diapause (SD) beetles reared under a short day condition, (B) changes in ovarian development during different developmental stages (I-V) in pre-diapause (upper) and pre-reproductive (lower) beetles, (C-F) developmental trajectory of the first accessory gland (FAG), second accessory gland (SAG), vas deferens (VD), and ejaculatory duct (ED), in pre-reproductive (LD) and pre-diapause (SD) beetles. All values are means \pm standard error. Values in (A) and (B) were estimated from 15 independent biological replicates. Values in (C-F) were estimated from 10 independent biological replicates. Asterisks indicate significant differences determined by an independent samples $t$-test $\left({ }^{*} p<0.05,{ }^{* *} p<0.01\right)$.

\subsection{Differences in Feeding Amount between Pre-Diapause and Pre-Reproductive Adult H. axyridis}

Changes in daily feeding amount in pre-diapause and pre-reproductive beetles were recorded at $20^{\circ} \mathrm{C}$. The daily feeding amount of both pre-diapause and pre-reproductive beetles initially increased and did not significantly differ for more than ten days (Figure 3). The food consumption of female pre-diapause beetles sharply decreased from the 15th day after eclosion (Figure 3A), whereas that of pre-diapause males decreased from the 14th day after eclosion (Figure 3B) (the 15th day: $t=-5.131$, $\mathrm{df}=28, p<0.001$, the 14th day: $\mathrm{t}=-2.534, \mathrm{df}=28, p=0.021$ ). Feeding amount of pre-diapause beetles then remained relatively low level, significantly lower than that of pre-reproductive beetles (Figure 3 ). 

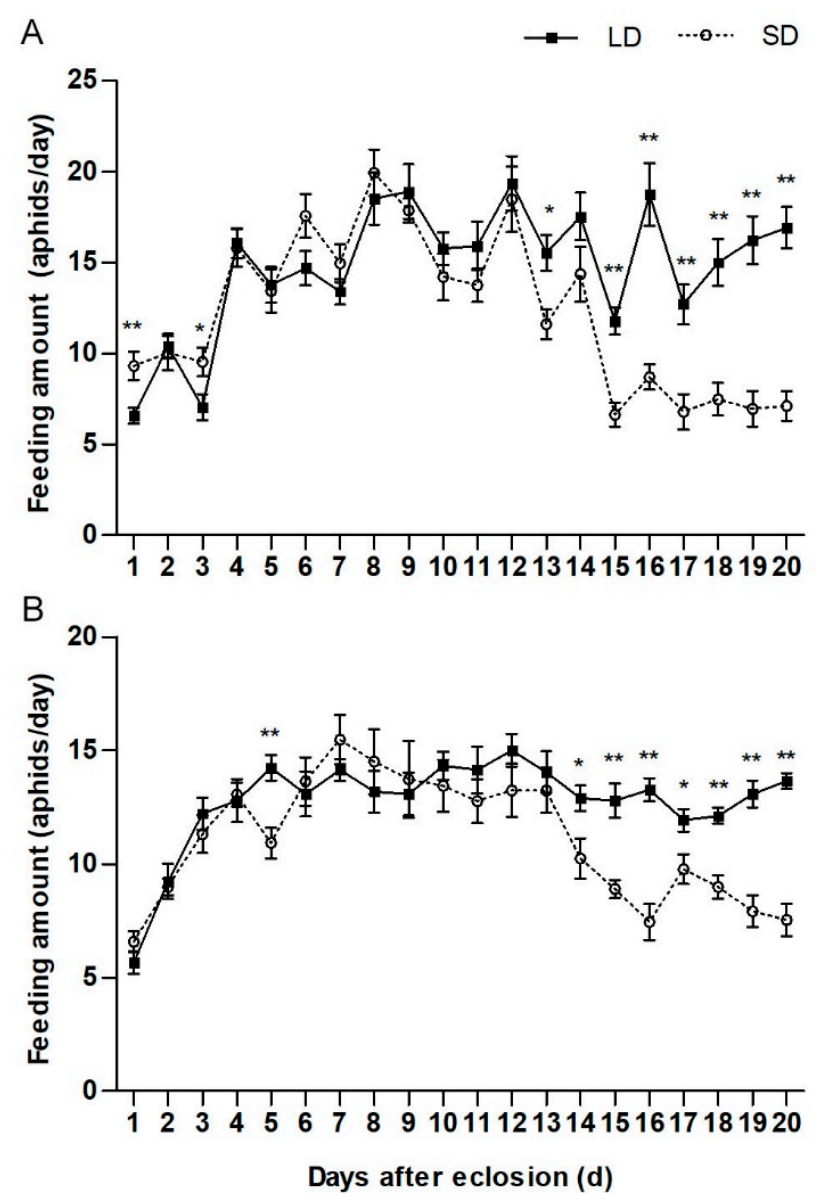

Figure 3. Dynamic changes in feeding amount in pre-diapause and pre-reproductive adult $H$. axyridis. Dynamic change in daily feeding amount of female (A) and male (B) H. axyridis. All values are means \pm standard error estimated from 15 independent biological replicates. $\mathrm{LD}=$ pre-reproductive beetles reared under a long-day condition and SD = pre-diapause beetles reared under a short-day condition. Asterisks indicate significant differences identified by an independent samples $t$-test $\left({ }^{*} p<0.05,{ }^{* *} p<0.01\right)$.

\subsection{Differences in Nutrient Storage between Pre-Diapause and Pre-Reproductive Adult H. axyridis}

The results indicate that both female and male pre-diapause beetles accumulated nutrients, and that these had accumulated more nutrients than pre-reproductive beetles after the 8 th day after eclosion (Figure 4). Female pre-diapause beetles accumulated nutrients by 20 days after eclosion and had accumulated approximately 1.6 times more carbohydrates and 1.87 times more lipids than pre-reproductive female beetles (carbohydrates: $\mathrm{t}=3.006, \mathrm{df}=8, p=0.024$; lipids: $\mathrm{t}=6.556, \mathrm{df}=18$, $p<0.001$ ). Pre-diapause male beetles only accumulated carbohydrates, and by 20 days after eclosion these had accumulated approximately 1.75 times more carbohydrates than pre-reproductive males $(\mathrm{t}=6.125, \mathrm{df}=8, p<0.001)$. There was no significant difference in the protein content of pre-diapause and pre-reproductive beetles of both sex (Figure 4A,D). 

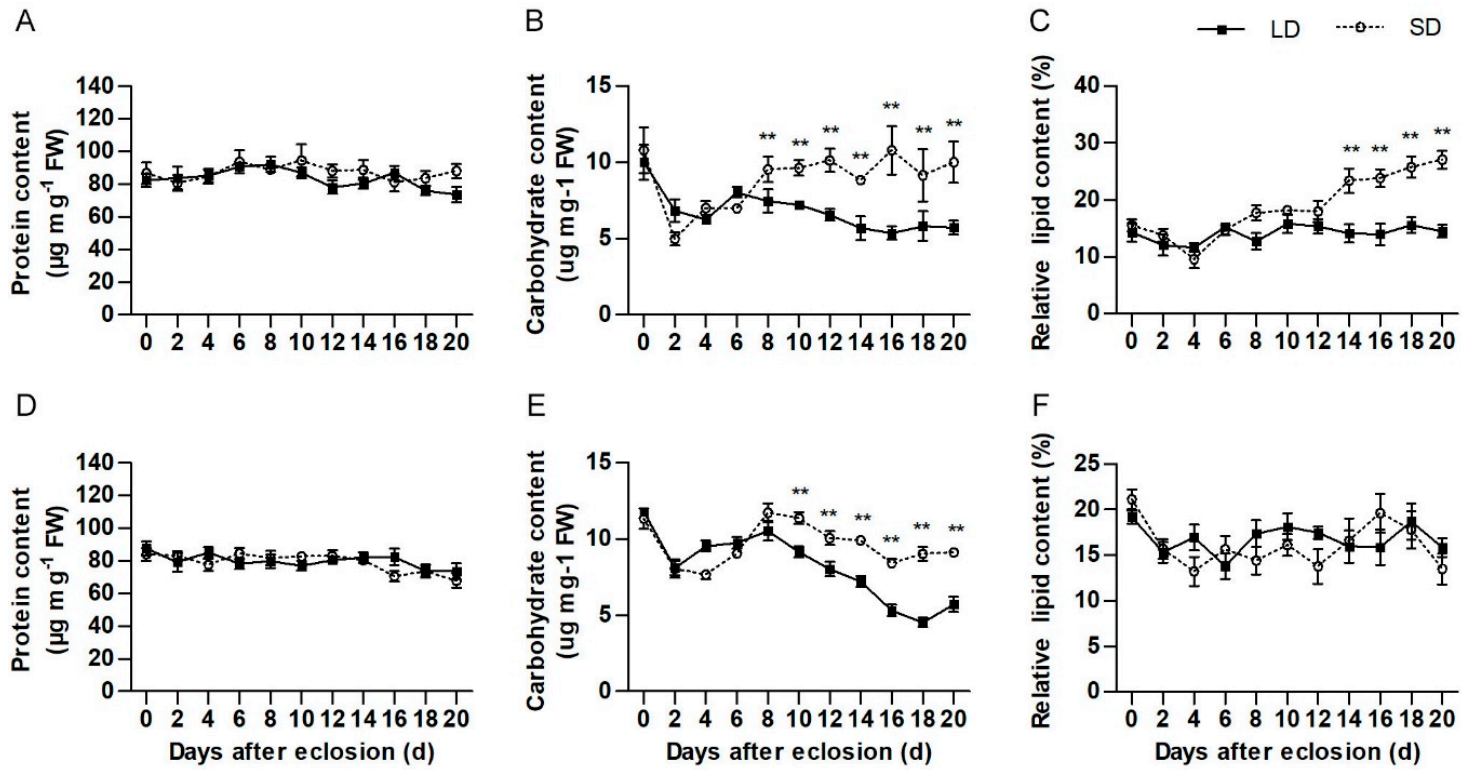

Figure 4. Differences in nutrient storage between pre-diapause and pre-reproductive adult $H$. axyridis. Protein accumulation in females (A) and males (D), Carbohydrate accumulation in females (B) and males (E), and lipid accumulation of females (C) and males (F). Values of protein and carbohydrate content are means \pm standard error estimated from 5 independent biological replicates. Values of lipid content are means \pm standard error estimated from 10 independent biological replicates. LD $=$ pre-reproductive beetles reared under a long-day condition and SD = pre-diapause beetles reared under a short-day condition. Asterisks indicate significant differences determined by an independent samples $t$-test $\left({ }^{*} p<0.05,{ }^{* *} p<0.01\right)$.

\section{Discussion}

Better understanding the diapause strategy of biological control insects could help the exploit of its commercial mass production based on diapause control [14]. However, key events during the pre-diapause stage in $H$. axyridis remain unclear. Our results showed that at the condition of $20{ }^{\circ} \mathrm{C}$ combined with SD condition, the first 15 and 14 days after eclosion could be considered as pre-diapause stage for female and male adults, respectively. The pre-diapause stage of H. axyridis was characterized by suppressed internal reproductive organs, a continuous increase in feeding amount, and the accumulation of lipids and carbohydrates. These results clarify the key period and events of the pre-diapause stage, and provide a basis for further utilization of diapause strategy in the commercial mass rearing and long-term storage of $H$. axyridis for use as a biological control.

Arrested development of the internal reproductive organs is one of the most remarkable characteristics of reproductive diapause [24,27]. We found obvious morphological differences in the ovary, vas deferens, ejaculatory duct, and accessory gland of pre-diapause and pre-reproductive H. axyridis. These differences were clearly visible and can be used as diagnostic indicators of diapause in future research. In addition, the differences were apparent relatively early, on the 4th day after eclosion for females and on the 6th day for males, which implies that photoperiod affect the diapause and reproductive decision at the early adult stage [22].

Sufficient nutrient storage before diapause is not only essential for diapause initiation and maintenance, but also for post-diapause fitness [24,28,37]. For example, sufficient food is necessary for both the boll weevil Anthonomus grandis grandis and two-spotted spider mite Tetranychus urticae Koch to enter diapause [38,39]. Bark beetles Ips typographus, with less nutrient reserves, have higher mortality and lower post-diapause fitness [40]. We found that lipids and carbohydrates were significantly accumulated in pre-diapause beetles. Interestingly, there were sexual differences in the nutrient storage of pre-diapause beetles; females accumulated carbohydrates and lipids, while male beetles accumulated carbohydrates only. These differences may be due to the different post-diapause activities 
of females and males. Lipids are important for ovarian development $[27,41]$, whereas carbohydrates provide most of the energy required for insect activity [27]. After diapause termination, male beetles become capable of mating as soon as females become receptive but have no further role to play in reproduction after mating is completed. Females, on the other hand, may need more energy reserves for egg maturation, and to search for suitable oviposition sites [24].

Insects increase their food intake prior to diapause to accumulate sufficient nutrient reserves to complete diapause successfully [27]. We found that the feeding amount of $H$. axyridis increased after eclosion and remained high for more than ten days after eclosion, with no significant difference in food amount between pre-diapause and pre-reproductive individuals during that period. There was a sharp decrease in the feeding amount of females from 15 days after eclosion, and in males, from 14 days after eclosion. This abrupt decrease in food intake and arrested development of the reproductive organs is a consistent feature of reproductive diapause insects $[27,28,42,43]$. The sharp decrease in feeding amount probably indicates the start of diapause in this beetle, because the differences in development of the internal reproductive organs and in the accumulation of carbohydrates and lipids both became statistically significant on the day that food consumption began to decrease. Therefore, under a temperature of $20^{\circ} \mathrm{C}$ and a SD condition, the period of pre-diapause stage is the first 15 and 14 days after eclosion for female and male adults, respectively. Before the long-term storage of diapause H. axyridis, this period should be fully considered for diapause inducing and preparation. Sufficient food was necessary during the pre-diapause stage while less food was needed after the start of diapause. However, further research is required to determine exactly when and what nutrients should be provided to improve both survival during the long-term storage of diapause $H$. axyridis and post-diapause fitness.

\section{Conclusions}

In conclusion, we identified the period of pre-diapause stage of female and male adult $H$. axyridis and clarified key preparatory events occurring in this stage: (1) at the condition of $20^{\circ} \mathrm{C}$ combined with SD condition, the first 15 and 14 days after eclosion was the pre-diapause stage of female and male adult H. axyridis, respectively; (2) during pre-diapause stage the development of internal reproductive organs was suppressed at early adult stage; (3) increasing of feeding amount and significant accumulation of carbohydrates and lipids were founded in pre-diapause stage. Our results not only provide a basis for further research related to the pre-diapause stage of $H$. axyridis, but also provide new clues for a better utilization of diapause strategy during mass production of this biocontrol species.

Author Contributions: Conceptualization, Q.G., W.L. and X.-P.W.; methodology, B.-X.W., Q.G. and J.-L.W.; formal analysis, B.-X.W. and Q.G.; writing original draft preparation, Q.G., X.-M.Z. and X.-P.W.; project administration, B.-X.W. and Q.G.; funding acquisition, J.-L.W.

Funding: This research was funded by the National Natural Science Foundation of China, grant number 31701842.

Conflicts of Interest: The authors declare no conflict of interest.

\section{References}

1. Kuroda, T.; Miura, K. Comparison of the effectiveness of two methods for releasing Harmonia axyridis (Pallas) (Coleoptera: Coccinellidae) against Aphis gossypii Glover (Homoptera: Aphididae) on cucumbers in a greenhouse. Appl. Entomol. Zool. 2003, 38, 271-274. [CrossRef]

2. Koch, R.L. The multicolored Asian lady beetle, Harmonia axyridis: A review of its biology, uses in biological control and non-target impacts. J. Insect Sci. 2003, 3, 1-16. [CrossRef]

3. Yano, E. Recent development of biological control and IPM in greenhouses in Japan. J. Asia Pac. Entomol. 2004, 7, 5-11. [CrossRef]

4. Riddick, E.W. Identification of conditions for successful aphid control by ladybirds in greenhouses. Insects 2017, 8, 38. [CrossRef] [PubMed]

5. Roy, H.; Wajnberg, E. From biological control to invasion: The ladybird Harmonia axyridis as a model species. BioControl 2008, 53, 1-4. [CrossRef] 
6. Brown, P.M.J.; Thomas, C.E.; Lombaert, E.; Jeffries, D.L.; Estoup, A.; Handley, L.J.L. The global spread of Harmonia axyridis (Coleoptera: Coccinellidae): Distribution, dispersal and routes of invasion. BioControl 2011, 56, 623-641. [CrossRef]

7. Roy, H.E.; Brown, P.M.J. Ten years of invasion: Harmonia axyridis (Pallas) (Coleoptera: Coccinellidae) in Britain. Ecol. Entomol. 2015, 40, 336-348. [CrossRef]

8. Bazzocchi, G.G.; Lanzoni, A.; Accinelli, G.; Burgio, G. Overwintering, phenology and fecundity of Harmonia axyridis in comparison with native Coccinellid species in Italy. BioControl 2004, 49, 245-260. [CrossRef]

9. Wang, H.T.; Zhang, W.D.; Chen, X.Z.; Zheng, J.F.; Miao, L.; Qin, Q.L. Mass rearing the multicolored Asian lady beetle on beet armyworm larvae. Chin. J. Appl. Entomol. 2012, 49, 1726-1731.

10. Sakurai, H.; Kawai, T.; Takeda, S. Physiological changes related to diapause of the lady beetle, Harmonia axyridis (Coleoptera: Coccinellidae). Appl. Entomol. Zool. 1992, 27, 479-487. [CrossRef]

11. Raak-Van den Berg, C.L.; De Jong, P.W.; Hemerik, L.; Van Lenteren, J.C. Diapause and post-diapause quiescence demonstrated in overwintering Harmonia axyridis (Coleoptera: Coccinellidae) in northwestern Europe. Eur. J. Entomol. 2013, 110, 585-591. [CrossRef]

12. Raak-van den Berg, C.L.; Hemerik, L.; De Jong, P.W.; Van Lenteren, J.C. Mode of overwintering of invasive Harmonia axyridis in the Netherlands. BioControl 2012, 57, 71-84. [CrossRef]

13. Reznik, S.Y.; Dolgovskaya, M.Y.; Ovchinnikov, A.N.; Belyakova, N.A. Weak photoperiodic response facilitates the biological invasion of the harlequin ladybird Harmonia axyridis (Pallas) (Coleoptera: Coccinellidae). J. Appl. Entomol. 2015, 139, 241-249. [CrossRef]

14. Denlinger, D.L. Why study diapause? Entomol. Res. 2008, 38, 1-9. [CrossRef]

15. Foerster, L.A.; Doetzer, A.K. Cold storage of the egg parasitoids Trissolcus basalis (Wollaston) and Telenomus podisi Ashmead (Hymenoptera: Scelionidae). Biol. Control 2006, 36, 232-237. [CrossRef]

16. Chen, W.L.; Leopold, R.A.; Harris, M.O. Cold storage effects on maternal and progeny quality of Gonatocerus ashmeadi Girault (Hymenoptera: Mymaridae). Biol. Control 2008, 46, 122-132. [CrossRef]

17. Zhang, H.Z.; Gao, F.; Liu, M.Y.; Wang, M.Z.; Han, Y.H.; Kong, L.; Chen, H.Y.; Liu, C.X.; Wang, M.Q.; Zhang, L.S. Research advances in diapause in small parasitic wasps in all the world in the last ten years. J. Environ. Entomol. 2018, 40, 82-91.

18. Ruan, C.C.; Du, W.M.; Wang, X.M.; Zhang, J.J.; Zang, L.S. Effect of long-term cold storage on the fitness of pre-wintering Harmonia axyridis (Pallas). BioControl 2012, 57, 95-102. [CrossRef]

19. Ongagna, P.; Iperti, G. Influence of temperature and photoperiod in Harmonia axyridis (Pall) (Col, Coccinellidae): Obtaining rapidly fecund adults or dormancy. J. Appl. Entomol. 1994, 117, 314-317. [CrossRef]

20. Berkvens, N.; Bonte, J.; Berkvens, D.; Tirry, L.; Clercq, P.D. Influence of diet and photoperiod on development and reproduction of European populations of Harmonia axyridis (Pallas) (Coleoptera: Coccinellidae). BioControl 2008, 53, 211-221. [CrossRef]

21. Reznik, S.Y.; Vaghina, N.P. Effects of photoperiod and diet on diapause tendency, maturation and fecundity in Harmonia axyridis (Coleoptera: Coccinellidae). J. Appl. Entomol. 2013, 137, 452-461. [CrossRef]

22. Zhang, W.; Liu, S.; Li, N.; Chen, J.; He, Y.Z.; Qin, Q.J. Effects of photoperiods on adult diapause of Harmonia axyridis (Pallas). Acta Phytophylacica Sin. 2014, 41, 495-500.

23. Kostál, V. Eco-physiological phases of insect diapause. J. Insect Physiol. 2006, 52, 113-127. [CrossRef] [PubMed]

24. Pener, M.P. Environmental cues, endocrine factors and reproductive diapause in male insects. Chronobiol. Int. 1992, 9, 102-113. [CrossRef] [PubMed]

25. Tan, Q.Q.; Feng, L.; Liu, W.; Zhu, L.; Lei, C.L.; Wang, X.P. Differences in the pre-diapause and pre-oviposition accumulation of critical nutrients in adult females of the beetle, Colaphellus Bowringi. Entomol. Exp. Appl. 2016, 160, 117-125. [CrossRef]

26. Urbanova, V.; Bazalova, O.; Vaneckova, H.; Dolezel, D. Photoperiod regulates growth of male accessory glands through juvenile hormone signaling in the linden bug, Pyrrhocoris apterus. Insect Biochem. Mol. Biol. 2016, 70, 184-190. [CrossRef] [PubMed]

27. Danks, H.V. Insect Dormancy: An Ecological Perspective; Biological Survey of Canada: Ottawa, Canada, 1987; pp. 19-82.

28. Hahn, D.A.; Denlinger, D.L. Energetics of Insect Diapause. Annu. Rev. Entomol. 2011, 56, 103-121. [CrossRef]

29. Denlinger, D.L. Regulation of diapause. Annu. Rev. Entomol. 2002, 47, 93-122. [CrossRef] 
30. Gautier, M.; Yamaguchi, J.; Foucaud, J.; Loiseau, A.; Ausset, A.; Facon, B. The genomic basis of color pattern polymorphism in the harlequin ladybird. Curr. Biol. 2018, 28, 3296-3302. [CrossRef]

31. Guo, C.F.; Xu, W.M.; He, Z.; Li, Y.H.; Ren, S.X.; Qiu, B.L. Color variations of Harmonia axyridis and phylogenetic analysis of 19-spot $H$. axyridis based on their COI genes. J. Plant Protect. 2016, 43, 155-161.

32. Sakurai, H.; Hirano, T.; Takeda, S. Physiological distinction between estivation and hibernation in the lady beetle, Coccinella septempunctata bruckii (Coleoptera, Coccinellidae). Appl. Entomol. Zool. 1986, 21, 424-429. [CrossRef]

33. Soares, A.O.; Coderre, D.; Schanderl, H. Effect of temperature and intraspecific allometry on predation by two phenotypes of Harmonia axyridis (Pallas) (Coleoptera: Coccinellidae). Environ. Entomol. 2003, 32, 939-944. [CrossRef]

34. Wasielewski, O.; Giejdasz, K.; Wojciechowicz, T.; Skrzypski, M. Ovary growth and protein levels in ovary and fat body during adult-wintering period in the red mason bee, Osmia rufa. Apidologie 2011, 42, 749-758. [CrossRef]

35. Dubois, M.; Gilles, K.A.; Hamilton, J.K.; Rebers, P.A.; Smith, F. Colorimetric method for determination of sugars and related substances. Anal. Chem. 1956, 28, 350-356. [CrossRef]

36. Folch, J.; Lees, M.; Stanley, G.H.S. A simple method for the isolation and purification of total lipides from animal tissues. J. Biol. Chem. 1957, 226, 497-509.

37. Hahn, D.A.; Denlinger, D.L. Meeting the energetic demands of insect diapause: Nutrient storage and utilization. J. Insect Physiol. 2007, 53, 760-773. [CrossRef]

38. Kawaguchi, S.; Manabe, Y.; Sugawara, T.; Osakabe, M. Imaginal feeding for progression of diapause phenotype in the two-spotted spider mite (Acari: Tetranychidae). Environ. Entomol. 2016, 45, 1568-1573. [CrossRef]

39. Spurgeon, D.W.; Suh, C.P.C.; Esquivel, J.F. Diapause response of the boll weevil (Coleoptera: Curculionidae) to feeding period duration and cotton square size. J. Insect Sci. 2018, 18, 9. [CrossRef]

40. Dworschak, K.; Gruppe, A.; Schopf, R. Survivability and post-diapause fitness in a scolytid beetle as a function of overwintering developmental stage and the implications for population dynamics. Ecol. Entomol. 2014, 39, 519-526. [CrossRef]

41. Liu, W.; Li, Y.; Zhu, L.; Zhu, F.; Lei, C.L.; Wang, X.P. Juvenile hormone facilitates the antagonism between adult reproduction and diapause through the methoprene-tolerant gene in the female Colaphellus bowringi. Insect Biochem. Mol. Biol. 2016, 74, 50-60. [CrossRef]

42. Dolezal, P.O.; Habustova, O.; Sehnal, F. Effects of photoperiod and temperature on the rate of larval development, food conversion efficiency, and imaginal diapause in Leptinotarsa decemlineata. J. Insect Physiol. 2007, 53, 849-857. [CrossRef]

43. Ito, K.; Fukuda, T.; Hayakawa, H.; Arakawa, R.; Saito, Y. Relationship between body colour, feeding, and reproductive arrest under short-day development in Tetranychus pueraricola (Acari: Tetranychidae). Exp. Appl. Acarol. 2013, 60, 471-477. [CrossRef]

(C) 2019 by the authors. Licensee MDPI, Basel, Switzerland. This article is an open access article distributed under the terms and conditions of the Creative Commons Attribution (CC BY) license (http://creativecommons.org/licenses/by/4.0/). 